\title{
ARQUITETURA BRASILEIRA DO IDEAL SOCIAL AO REPERTÓRIO CENOGRÁFICO
}

\author{
Derick Sanches, Luciana Bernardes, Mariane Garcia, Korina Costa \\ Universidade do Oeste Paulista - UNOESTE. Curso de Arquitetura e Urbanismo, Presidente Prudente - SP. E-mail: \\ korina.arq@gmail.com
}

\begin{abstract}
RESUMO
A arquitetura contemporânea brasileira apresenta influencias dos projetos modernistas de Vilanova Artigas, abstraindo a ilusão do papel de transformação social do período de 1940 a 1950, tomando como linguagem a prática do projeto e não mais como ideologia. Esta linguagem pode ser percebida na produção arquitetônica de Isay Weinfeld, como também inspirações para projetos contemporâneos. Na trajetória e pensamento de Artigas é exaltado como ação projetual a vivencia social-espacial transformando o espaço em um "espaço democrático". Artigas imaginava que nessas residências poderia, em termos técnicos, conseguir resolver os problemas da casa popular, além do que, nelas poderiam se antecipar as futuras modificações sociais desejadas. Contudo, no atual momento, e de acordo com a produção arquitetônica estudada do arquiteto Isay Weinfeld o espaço torna-se "palco", com sua iluminação cênica de modo a conduzir o usuário, criando diferentes sensações.
\end{abstract}

Palavras-chave: Arquitetura Moderna; Arquitetura Contemporânea; Vilanova Artigas; Isay Weinfeld; Arquitetura de consumo.

\section{BRAZILIAN ARCHITECTURE OF SOCIAL IDEAL TO THE SCENOGRAPHIC REPERTORY}

\begin{abstract}
The Brazilian contemporary architecture has influences of modernist projects Vilanova Artigas, abstracting the illusion of the role of social change in the period 1940-1950, taking language as the practice of design and not as an ideology. This language can be seen in the architectural production of Isay Weinfeld, as well as inspirations for contemporary designs. The trajectory and Artiga's thought is exalted as projectual social action-spatial experiences transforming the space into a "democratic space". Artigas imagined that these houses could, technically, be able to solve the problems of popular home besides that, in them could anticipate future desired social changes. However, at present, and according to architectural production Isay Weinfeld Architect studied the space becomes "stage", with its scenic lighting so as to lead the user, creating different sensations. Keywords: Modern Architecture; Contemporary architecture; Vilanova Artigas; Isay Weinfeld; Architecture consumption.
\end{abstract}




\section{INTRODUÇÃO}

Neste artigo será abordada a importância da produção arquitetônica de João Vilanova Artigas e suas reflexões sobre os ideais modernistas e sua postura de cunho político-socialista materializado neste recorte que é a Casa Olga Baeta. O estudo desta obra exemplifica o caráter de função social do arquiteto e suas aflições diante das disparidades da sociedade brasileira da década de 50 e a busca por uma linguagem própria que expressasse a habitação da vida contemporânea. Artigas prega o "desenho" como a arma mais eficaz do arquiteto para se manifestar criticamente, o desenho como desígnio, ou seja a intenção de ser um agente transformador da sociedade.

Influenciado pelo design Isay Weinfeld, arquiteto contemporâneo, tem em suas produções principalmente residenciais um caráter cênico, onde o mesmo proporciona diferentes ambientações, buscando o conforto tanto psicológico quanto físico de quem ali habita.

Sendo assim, através da análise de obras de ambos os arquitetos objetiva-se buscar um parâmetro provindo dos moldes da arquitetura moderna paulista, sob toda a influência de Vilanova Artigas com a qual, procurando entender então, meio a analises, a arquitetura na contemporaneidade, sendo ela observada através de obras do Isay Weinfeld.

\section{METODOLOGIA}

A metodologia busca traçar uma relação individualidade e coletividade nas arquiteturas de Vilanova Artigas e Isay Weinfeld, por meio de analise de obras de ambos, conceitos do Brutalismo Brasileiro e da Escola Paulista, e da Arquitetura Brasileira na Contemporaneidade, assim como sua relação com o entorno e incerção no meio urbando. Cuja investigação se fundamentará na abordagem qualitativa de pesquisa, utilizando-se da pesquisa de levantamento bibliográfico e da pesquisa documental, que segundo Teixeira (2000, p. 137), busca a correlação entre a teoria e os dados, entre o contexto e a ação, a partir da compreensão dos fenômenos por meio de sua descrição e interpretação. Para o trabalho com o estudo do tipo de levantamento bibliográfico ocorrerá inicialmente um levantamento das principais produções no contexto nacional de estudos, considerando a peculiaridade do objeto de estudo.

Desse modo, percebe-se que a pesquisa qualitativa vale-se do método indutivo, segundo o qual parte da observação, da análise dos fatos particulares, dos registros para compor um quadro compreensivo para então constituir a generalização universal, ou seja, a teoria. 0 processo de indução vale-se do princípio do empirismo, no qual o conhecer é dar significado à realidade (KÖCHE, 1997, p. 62). 
TRAJETÓRIA DO PENSAMENTO E OBRA DE VILANOVA (1915 - 1985)

João Batista Vilanova Artigas formou-se Engenheiro-Arquiteto pela Escola Politécnica da Universidade de São Paulo, em 1937. Ainda estudante, envolveu-se com o Grupo Santa Helena, um coletivo de artistas de vanguarda, onde pôde desenvolver suas habilidades com desenho. Apesar de curitibano, foi em São Paulo que desenvolveu e consolidou a sua carreira, tendo atuado tanto em escritório como na carreira acadêmica. Foi professor da FAU USP, escola que ajudou a fundar, e a reformular o currículo, e cujo projeto arquitetônico é de sua autoria.

Sua arquitetura é associada ao movimento arquitetônico Escola Paulista , e se caracteriza pela verdade e plasticidade estrutural, a exploração da estética do concreto, a presença de cores fortes, a valorização de espaços coletivos em detrimento dos individuais - característica que traduzia os seus ideais políticos. Filiado ao partido comunista, Artigas foi exilado pelo governo militar, retornando ao Brasil e ao ensino em 1979. A historiografia considera que a sua obra se dividiu em três grandes fases: uma primeira, inspirada por Frank Lloyd Wright, uma segunda, racionalista corbusieriana, e a última, inspirada pela arquitetura tardia de Le Corbusier e brutalismo. Faleceu em 12 de janeiro de 1985.

\section{OBRA DE REFERÊNCIA DE ESTUDO - CASA OLGA BAETA - 1956}

O projeto desta casa é considerado o divisor de águas na produção de Artigas, o arquiteto inicia a busca por uma linguagem própria, esta depois considerada a escola paulista de arquitetura a partir da metade da década de 1950.

Artigas consagra-se como o poeta das estruturas, onde a estética do concreto armado e a busca em reduzir ao mínimo os pontos de apoio e ao mesmo tempo levá-los à máxima expressão é uma constante na produção do arquiteto.

Para Artigas, cabe aos arquitetos contribuir para um projeto de desenvolvimento nacional. Mais do que uma busca puramente estética ou técnica, o emprego do concreto armado e protendido, revelam um projeto político para o país, que aposta na industrialização para a superação do subdesenvolvimento, algo que só poderia ser realizado pelo investimento na modernização técnica da construção civil e a racionalização do desenho.

As ranhuras deixadas no concreto armado da casa Olga Baeta são as imperfeições de uma arquitetura produzida manualmente, ao contrário do ideário mecanicista, passam a ser a tradução do arcaísmo dos materiais empregados, das falhas originadas no processo construtivo e das adversidades enfrentadas pela baixa qualidade da mão de obra. Dessa maneira, as desventuras 
para a consecução de uma mudança de paradigma passam a ser parte visível das discrepâncias presentes na condição socioeconômica do país.

Na Casa Olga Baeta, o arquiteto consegue expressar formalmente a dificuldade de uma relação franca e otimista entre edifício e cidade, concebendo "construções introvertidas", cujas faces externas são empenas cegas.

A casa Olga Baeta busca romper com uma inter-relação com o entorno porque, ao contrário da liberdade formal dos desenhos sinuosos das marquises e das transparências que propunham a ligação interior-exterior da Escola Carioca, ela também se opõem como critica à estética do mercado imobiliário paulistano.

Com a especulação do solo urbano e lotes cada vez menores em São Paulo, Artigas busca demonstrar a inadequação de se construir uma arquitetura em contato com o exterior e procura uma nova organização espacial para a casa paulista refutando a tradicional espacialidade compartimentada da casa burguesa. Desse ponto de vista, Artigas, acaba abolindo a garagem como "cocheira" e as dependências de serviço localizadas numa edificação separada, são unificadas ao corpo da casa. Também consegue eliminar corredores, definindo desníveis que são fruídos espacialmente. As salas e estúdio têm pé-direito alto e o vazio formado acima desses ambientes permite que sejam vistos e integrados espacialmente à circulação do pavimento superior.

As áreas dos ambientes das salas são definidos por cores diferenciadas pintadas no piso de cada ambiente lembrando uma obra de Mondrian. Com isso, Artigas argumentava que a definição da área de influência de cada ambiente, os limites para a realização de atividades especificas e pertinentes a cada espaço, deveria ser percebida pelo usuário em função da espacialidade proposta pelos planos coloridos do piso e não pelas paredes. A circulação horizontal no térreo se dá pelos ambientes e no pavimento superior, uma espécie de corredor com largura variável é o local de passagem entre os quartos e os sanitários. Uma escada escultural toda preta é o elemento arquitetônico para a circulação entre os dois pisos da residência. Os dormitórios do pavimento superior estão com os caixilhos orientados para a face norte, lateral direita do lote. Os caixilhos dos dormitórios do pavimento superior são em grandes painéis de madeira de piso a teto e pintados na cor vermelha como as calhas nos beirais do telhado, enquanto que os pilares estão pintados na cor azul escuro.

\section{ISAY WEINFELD E A DRAMATICIDADE NOS ESPAÇOS}

De acordo com o livro Isay Weinfeld editora BEI (2008) Isay nasceu em 1952 na cidade de São Paulo, formou-se em 1975 pela FAU/Mackenzie onde lecionou teoria da arquitetura e foi 
professor da cadeira de "Expressão Cinética" pela Faculdade Álvares Penteado. Foi o responsável pelo projeto arquitetônico da montagem da exposição "BMW- Art Car Collection" ocorrida em São Paulo no ano de 1994 no Masp e na cidade do Rio de Janeiro, no Museu de Arte Moderna (MAM). No ano de 2005 participou da exposição "Encore Moderne? Architecture Contemporaine ou Brésil?" no Institut Français d'Architecture como expositor e palestrante e da "VI Bienal Internacional de Arquitetura de São Paulo" com o projeto "Praça da Amauri" agraciado com o prêmio Ex-Aequo. Em 2008 recebeu o prêmio Yellow Pencil realizado em Londres pelo projeto da Livraria da Vida (ISAY WEINFELD EDITORA BEI 2008). Além de ser um designer em evidência na atualidade, a arquitetura produzida por Isay principalmente no âmbito residencial revela seus diversos interesses e sua sensibilidade multifacetada. (BARRENECHE, 2008). Ainda no pensamento de Barreneche (2008), a paixão do arquiteto pelo cinema e palco está em eminência na maneira com que organiza a circulação, na qual um corredor é em si mesmo uma experiência sensorial e não somente a ligação entre os cômodos; já uma sacada apresenta o caráter dramático de um palco graças ao adorno proporcionado pelas cortinas flutuando ao vento. Segundo Anderson Almeida (2012) na arquitetura contemporânea, alguns designers de interiores e arquitetos se utilizam do recurso da cenografia para compor seus projetos e adequá-los a uma atmosfera cênica, onde o usuário do espaço é conduzido a experimentar sensações. Desta maneira o arquiteto brasileiro Isay Weinfeld, inspira-se no teatro para elaborar a concepção projetual em seus projetos de interior. Como cineasta o arquiteto conduz o visitante por uma seqüência especifica de experiências táteis, visuais e espaciais. (ANDERSON ALMEIDA, 2012)

\section{OBRA DE REFERÊNCIA DE ESTUDO - CASA SUIÇA - 2001}

Na Casa Suiça projetada em 2001 por Isay Weinfeld e localizada em São Paulo, o acesso acontece pelo pavimento inferior. Externamente há uma espécie de hall vinculado aos funcionários que conduz à área de serviço e dependência destes. A casa foi projetada para um empresário do ramo musical. O proprietário organiza com freqüência festas e jantares ,recebendo convidados, portanto, foi necessária a criação de um acesso pessoal, isto é, para os moradores e um acesso social para receber os visitantes, ambos no pavimento inferior, contudo o primeiro contém uma caixa de escada que conduz o transeunte até o pavimento térreo em um hall interno intimo de entrada para a área de vivência onde estão a copa, sala de estar e home, ou para os dormitórios e suíte no pavimento superior; já no segundo acesso (social) os convidados têm livre trânsito pela casa até a área de vivência. Assim como no período colonial brasileiro em que os senhores de engenho e sua família habitavam a casa grande e os escravos a senzala, a própria 
estrutura arquitetônica contemporânea em estudo se divide em dependência de moradores e dependência de funcionários, apresentando a mesma segregação e indo contra os preceitos de Vilanova Artigas. (ISAY WEINFELD EDITORA BEI 2008)

Na produção contemporânea, assim como na Casa Suiça é notória a postura e linhagens presentes em edifícios concebidos pela primeira geração de modernistas brasileiros. Os pavimentos acontecem em diferentes níveis de piso interligados por degraus e escadas, criando a setorização dos espaços internos e a área de vivência apresenta ambientes integrados e amplos característica do arquitetura contemporânea. (RICARDO FERREIRA, 2010)

Da rua a casa parece ser compacta com uma única abertura na fachada, na qual se combinam massa pintada e tijolo de demolição, é uma pequena sacada de aço corten que se projeta sobre o portão revestido de chapas de alumínio. Nos fundos há uma sala de jantar com pé direito de 7 metros e que se abre para o jardim externo por meio de portas corrediças de vidro possibilitando as "grandes aberturas modernistas" que resgatavam a relação da paisagem com o meio físico.

Como na Planta "centrífuga" modernista e em diversas obras de Isay Weinfeld, o corredor é o elemento articulador entre os espaços e forma um sistema interligando os demais espaços afastados desse centro, seguindo uma hierarquia. Na Casa Suiça a suíte do casal contém closet, área de home Office e banheiro, ocupando quase $50 \%$ do pavimento superior, além de englobar um amplo balcão e o espaço oferecer vistas da sala de estar e jardim. No terraço há um espaço para celebrações. Isay em seus projetos residenciais demonstra o conhecimento pleno sobre os materiais que virão a ser empregados, mescla o abstrato com o tátil, cria volumes grandes com superfícies detalhadas em madeira (ipê, perobinha e sucupira), em pedra portuguesa ou ainda utiliza texturas. Os interiores, das áreas de estar e jantar no térreo aos quartos no piso superior mistura o rústico e o refinado. (RICARDO FERREIRA, 2010)

\section{CONCLUSÃO}

Tanto para a arquitetura internacional quanto para a nacional, o modernismo buscou concretizar o conforto as moradias. Sabe-se que desde o século XVIII, profissionais já presavam o conforto térmico das residências, e futuramente, o conforto seria inserido também ao que se diz respeito ao bem estar físico e psicológico de quem ali reside.

Para Artigas o Partido Arquitetônico não era meramente a resposta as condicionantes, necessidades e as expectativas do usuário, mas uma procura pela definição de conceitos que norteassem uma arquitetura com identidade nacional, imbuído de uma "moral construtiva". A 
partir da revisão de aspectos sociais de nossa cultura, ele propõem um novo modo de habitar, mais adequados aos novos usos e costumes.

No cenário nacional, vivemos então resquícios de uma cultura nativa somada ao Brasil pós Brasília, onde na década de 40 e 50, viveu uma enorme demanda de construção comercial unida a falta de liderança cultural. O papel do arquiteto, aquele que ingressava na profissão com o objetivo social de melhorar a qualidade de vida da população, se extinguiu após a década de 60 . Esta época marca as características arquitetônicas de cunho social se tornando objetos de consumo.

$\mathrm{Na}$ arquitetura do séc. XXI é perceptível a efemeridade e o consumismo trazida do profissional ao cliente, buscando uma "tendência" adquirindo uma nova versão ou modelo que são impostas pelo mercado.

\section{REFERÊNCIAS}

ACAYABA, Marlene Milan. Residência Olga Baeta (1956-1957). In: Residências em São Paulo: 1947-1975. São Paulo: Romano Guerra Editora, 2011. http://www.architecturalpapers.ch/index.php?ID=39

ARTIGAS, Vilanova. A função social do arquiteto. São Paulo: Nobel-Fundação Vilanova Artigas, 1989. Esse conjunto de arguições foi posteriormente incorporado em: ARTIGAS, Vilanova. Caminhos da arquitetura. São Paulo: Cosac \& Naify, 2004.

ARTIGAS, Rosa; LIRA, José Tavares Correia de (Orgs.). Caminhos da arquitetura. Vilanova Artigas. Coleção Face Norte, volume 08. 4a edição, São Paulo, Cosac Naify, 2004.

KAMITA, João M. Vilanova Artigas. São Paulo: Cosac Naify, 2000.

KATINSKY, Julio R (Cur.). Vilanova Artigas. São Paulo: Instituto Tomie Ohtake, 2003, p.24-239.

KÖCHE, J. C. Fundamentos de metodologia científica: teoria da ciência e iniciação à pesquisa. 22. ed. São Paulo: Vozes, 2004.

IRIGYEN, Adriana - Wright e Artigas: Duas viagens. Ateliê Editorial. São Paulo, 2002.

PETROSINO, Maurício Miguel. João Batista Vilanova Artigas - Residências unifamiliares: a produção arquitetônica de 1937 a 1981. São Paulo: FAU/USP, 2009.

PIZA, Daniel; Perfis e entrevistas Escritores, Artistas, Cientista; Editora Contexto. 2004.

ALMDEIDA, Anderson; A dramaticidade nos espaços projetados por Isay Weinfeld; Instituto Federal de Alagoas 2006. Disponível em $<$ http://semanaacademica.org.br/system/files/artigos/artigoisay.pdf $>$, acessos em 27 de maio de 2014. 
FERREIRA, Araújo; TINEM, Nelci; COTRIM, Marcio; Arquitetura Residencial Moderna em João Pessoa nos anos de 1970; ano 11, novembro de 2010. Disponível em <http://www.vitruvius.com.br/revistas/read/arquitextos/11.126/3651 >, acessos em 22 março de 2014.

GRUNOW, Evelise; Materiais Sinalizam a Setorização Vertical; Texto publicado originalmente em Projeto Design Edição 350. Disponível em < http://arcoweb.com.br/projetodesign/arquitetura/isayweinfeld-residencia-sao-24-04-2009 >, acessos em 20 de março. 2014.

SILVA, Helga Santos; O Conforto na Arquitetura Moderna Brasileira; fevereiro de 2009; Disponível em: Risco: Revista de Pesquisa em Arquitetura e Urbanismo (Online). <http://www.revistas.usp.br/risco/article/view/44782>

TEIXEIRA, E. As três metodologias. 2a .ed. São Paulo: Vozes, 2000.

MAHFUZ, Edson da Cunha; A arquitetura consumida na fogueira das vaidades; dezembro de 2000; Disponível em <http://www.arquitetando.xpg.com.br/texto\%20nPAl01.htm> 